\title{
Frankenfish, Monsatan, and Killer Canola Making Good Decisions in the Midst of Environmental Controversy
}

\author{
H. A. Longstaff* \\ The W. Maurice Young Centre for Applied Ethics, the University of British Columbia, 227-6356 Agricultural Road, \\ Vancouver, BC V6T 1Z2, Canada
}

\begin{abstract}
On January 9th 2004, the journal 'Science' confirmed that farmed salmon is higher in industrial pollutants called polychlorinated biphenyls (PCBs) and other toxins than wild salmon. The fishmeal component of the farmed salmon feed was cited as the likely source of these contaminants. One way to avoid this toxin loading is to use a salmon feed that contains genetically engineered (GE) ingredients. This new feed would substitute wild South American fish meal for transgenic canola as its main protein component. Although this option has many environmental, social, and economic benefits for Canadian consumers, it will also likely be met with opposition from certain special interest groups, and become a popular target of the media. The Canadian salmon aquaculture industry has in some cases been vilified by the popular media and certain environmental non-governmental organizations (ENGOs). Whether this portrayal is justified or not is debatable. What we do know is that an excessive amount of conflicting information makes effective decision making extremely difficult for Canadian consumers. Information concerning transgenic feeds can be highly complex and unfamiliar to many laypeople. Our research demonstrates that the public already holds misconceptions regarding the salmon aquaculture industry. These misconceptions hinder an individual's ability to make good decisions about salmon aquaculture food products, and must be addressed before this industry attempts to disseminate additional information concerning new controversial technologies (i.e., transgenic feeds). We have found that it is possible to effectively communicate the risks and benefits of controversial issues while addressing misconceptions through a process known as the mental models approach to risk communication, as described by Morgan et al., 2002. This paper discusses the results of our risk communication experiment and shows how this process affected our respondents' understanding of factual information, their confidence as consumers, their acceptance of this issue, and their purchasing decisions.
\end{abstract}

Keywords: Genetically engineered feeds, mental models, risk communication, salmon aquaculture

\section{Introduction}

Members of the general public regularly make decisions about complicated issues in short periods of time with incomplete information. For example, while making foodpurchasing decisions, individuals typically consider the nutritional content and price of the product, and how that product will affect the health and wellbeing of their family. Many consumers now realize that what may appear to be a mundane purchasing decision can actually have significant impacts to people and ecosystems in other regions of the globe. When consumers consider purchasing products that contain genetically-engineered (GE) ingredients, they should be aware of the range of consequences that their decision will have on the farmers who grew the crop, the environment in which the crop was grown, and the company that owns the technology, among other things.

The price, nutritional content, ethical, and environmental impacts of a product amount to a great deal of information to consider while waiting in line at the grocery store. Many peo-

\footnotetext{
* Corresponding author: longstaf@interchange.ubc.ca
}

ple do not have the requisite time and energy to research each of their purchasing decisions. As well, a significant portion of our interview respondents admitted that they did not know where to access information concerning salmon aquaculture food products, provided that it was in fact available to the general public. Risk communication is a tool that can be utilized to help increase confidence levels for consumers while allowing them to make informed decisions that align with their values and beliefs.

This paper discusses the results of the final portion (in person survey) of a risk communication experiment conducted during the spring and summer of 2003. The motivation is to examine how different communication methods affect an individual's understanding of factual information, their confidence as a consumer, their acceptance of an issue, and their purchasing decisions. The following section will provide a description of the topic used for this experiment. This paper discusses the mental models approach in a novel context rarely addressed in the past. The topic chosen is GE feeds that may be utilized by the Canadian salmon aquaculture industry in the future. We also experiment with different methods of communication, a step rarely taken in the study of risk. 


\subsection{Background}

Canadian consumers are often bombarded by messages from the media intended to manipulate them into watching a particular broadcast or reading a particular paper. If a product is given widespread attention by the popular media, that product may be perceived as hazardous by the viewer despite scientific evidence to the contrary (Health Canada, 2004).* For this reason, risk communication literature often describes the media as an amplifier of risk. As explained by Roger Kasperson, the social impacts of even minor events can be extreme if those events are covered extensively through the media.

Since the media tend to accord disproportionate coverage to rare or dramatic risks, or risk events, it is not surprising that people's estimates of the principal causes of death are related to the amount of media coverage they receive. (Kasperson et al., 1988)

Yet the media is only one, among a myriad of factors that can influence an individual's purchasing decisions. Other significant factors include that individual's values, their comfort taking risks, and the trust they have in the body or individual disseminating the information. The objective of this research paper was to experiment with different methods of disseminating complex information in order to help consumers make good decisions. We chose to use GE inputs for salmon aquaculture food products as our topic because of this issue's controversial nature.

Two years after a seven year moratorium was lifted on the salmon aquaculture industry in British Columbia (BC), the journal 'Science' confirmed that farmed salmon is higher in industrial pollutants called polychlorinated biphenyls (PCBs) and other toxins than wild salmon. The fishmeal component of the farmed salmon feed was cited as the likely source of these contaminants. This finding re-ignited the controversy that has surrounded this industry since its inception along the coast of BC in the mid 1980s.

Currently, the main protein component in farmed salmon feed includes wild fishmeal and fish oil from South America. One way to avoid introducing PCBs into the diet of a farmed salmon is to substitute Canadian grown high protein plants like canola for South American wild fish meal as the main protein component in fish feed. However, if the industry decides to pursue this alternative, the plant would have to be modified, as carnivorous salmon cannot digest the phytic acid in canola. One solution is to genetically engineer the canola into a low-phytate plant. ${ }^{* * * *}$ Yet this is not the only benefit

\footnotetext{
* The Journal Science recently published the results of a study that found farmed salmon higher in PCBs than their wild counterparts. Since then, this study has been reported on extensively through the media. However, although levels of PCBs do seem to be higher in farmed salmon, these levels are still below Health Canada's current guidelines which are consistent with guidelines set by both the U.S Food and Drug Administration (FDA) and the World Health Organization (WHO).

** It should also be noted that genetically engineering the canola plant is only one option available to the salmon aquaculture industry.
}

associated with using GE canola in fish feeds. Substituting GE canola for South American wild fishmeal and oil would also reduce overall production costs for Canadian aquaculturalists.

Experts from Fisheries and Oceans Canada report that feed costs for British Columbian salmon aquaculturalists are already approximately $35-60 \%$ of their total production costs (Key informant interviews with employees of the Department of Fisheries and Oceans Canada, 2003). The protein component makes up approximately $50 \%$ of the feed costs and fishmeal makes up roughly 25 - 50\% (by weight) of the protein component. Consequently, finding an alternative, stable, and non-toxic source of local protein and oil for fish feeds would be both economically advantageous to the Canadian aquaculture industry and socially advantageous to consumers in terms of human health.

\section{Methods}

Risk communication has traditionally been performed in an ad hoc fashion and viewed as a public relations exercise instead of a vital component of responsible management (Branswell, 2004). Researchers at Carnegie Mellon University believed that it was possible to improve the overall effectiveness of public risk communication by developing a more systematic approach. Their mental models approach to risk communication is a technique that can be utilized to help consumers make informed decisions. This communication tool acknowledges the external and internal influences on our choices, while presenting complex information in an organized way.

As explained by Granger Morgan et al, each individual will have pre-existing knowledge structures or "mental models" of how their complex world operates (Morgan et al., 2002). These models are informed by that person's life experiences or worldview and are often incorporated into the individual's decision making processes. However, these models are simplifications, like any model, and can therefore be inaccurate or incomplete. Partial mental models, or models that contain misconceptions, can hinder the ways in which we comprehend new risk information. The purpose of the mental models approach is to uncover what the public's perceptions, or a priori knowledge, of certain issues are. Once these models are examined, expert information can be organized into a

In order to make larger quantities of canola digestible to animals, the industry could also choose to genetically engineer the salmon, treat the unmodified canola with phytase or subject it to high temperature treatments. The genetic engineering option was chosen as the topic for this research study because of its controversial nature and because it has the potential to be a socially undesirable option. Also, Fisheries and Oceans Canada is currently interested in this topic. For more on this subject, please refer to Fisheries and Oceans Canada's Biotechnology Topics at <http://www.pac.dfo-mpo.gc.ca/aquaculture/ topics/salmonfeed_e.htm>

*** It would also likely be engineered in ways that would make it more economically efficient to grow. Some of the latter modifications may include herbicide, frost, or pest resistance. 


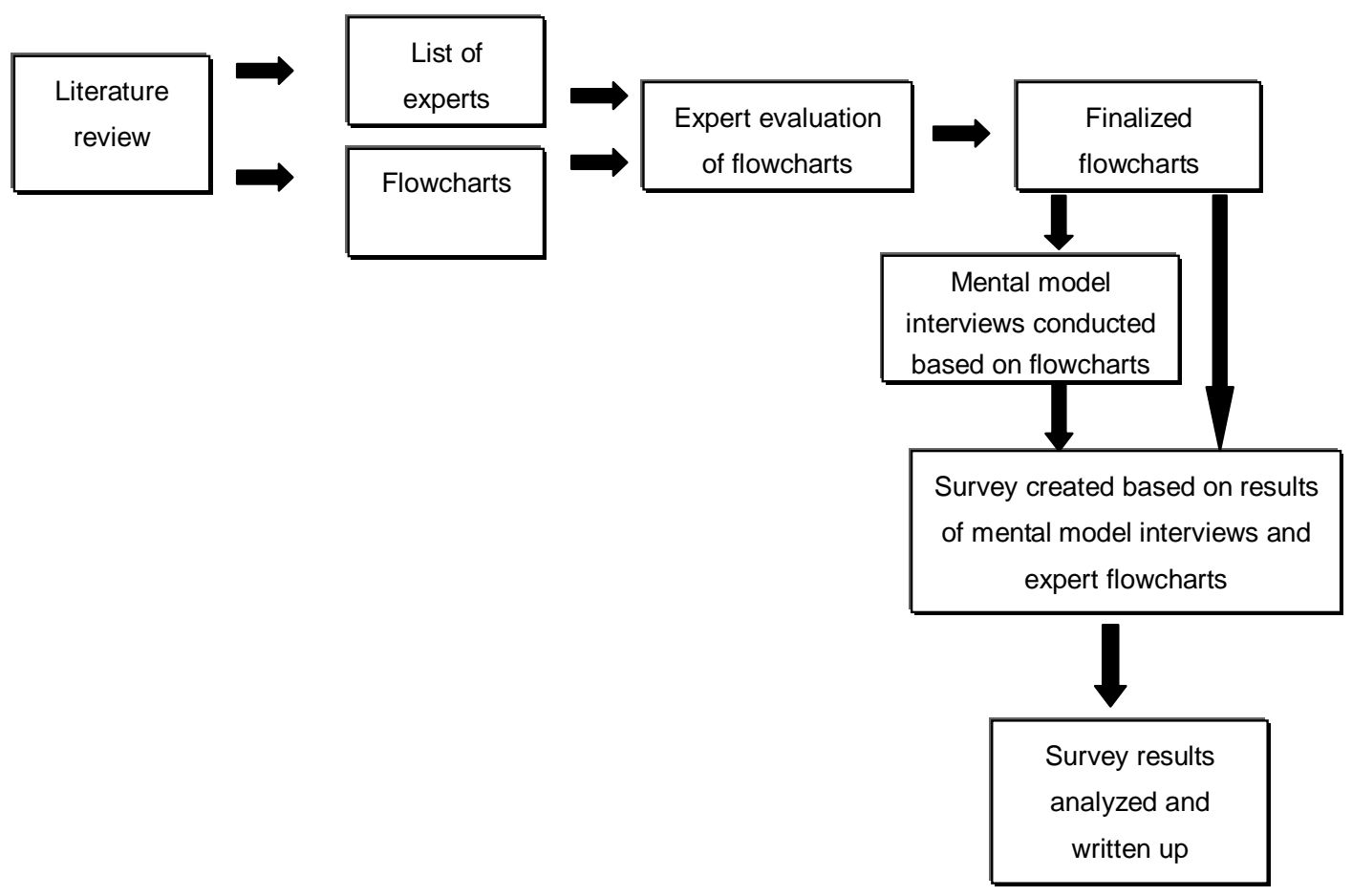

Figure 1. Conceptual framework for the mental models approach.

format that effectively speaks to them by alluding to major uncertainties or points of common interest.

I argue that the mental models method is also an ethical approach to risk communication because unlike other methods, it attempts to minimize bias through the use of a diverse expert panel. In the mental models process, the known risks and benefits of the product in question are determined by a group of experts who represent a diverse understanding of the topic, one that reaches beyond a conventional scientific standpoint.* The expert panel must determine the validity of the information that will ultimately guide the risk communication experiment. As such, the diverse nature of this group will prevent bias from entering into the public risk communication materials. The dissemination process thus gives consumers the opportunity to think through many of the risks and benefits associated with their choices while making informed purchasing decisions that align with their values and beliefs. Essentially, this process invites the risk communicator, expert, and layperson to work together to understand the acceptability of certain risks.

\section{Materials}

The conceptual framework for this research paper in-

\footnotetext{
*Although a panel will typically include many scientific experts, the panel may also include expert environmentalists, individuals who have a specific medical condition, etc.
}

volves four tasks and is based on the work of Granger Morgan et al (see Figure 1) (Morgan et al., 2002). As mentioned, this paper focuses on the final stage of this experiment, the results of the in person survey. The process began by conducting an extensive literature review in order to complete three flowcharts that categorized the known economic, social, and environmental risks and benefits of using GE farmed salmon feed, which is the topic of interest in this paper. These charts were then distributed to a diverse set of experts who were asked to determine the validity of their content. ${ }^{* *}$ Uncertainties were built into the charts by illustrating the consequences of many possible decision pathways and by explicitly stating where current knowledge was limited or uncertain. Each respondent was also told that the risk communication materials they were viewing represented the current state of expert knowledge concerning the topic and could potentially change in the face of new discoveries.

Once these two stages were complete, sixteen interviews were conducted with volunteer members of the general public. These interviews were intended to clarify and establish the mental models of our respondents and act as a basis for risk communication. During these interviews, it was determined that many people held common misconceptions regarding salmon aquaculture and GE technologies. These misconcep-

\footnotetext{
** As many of the issues addressed in this experiment were highly complex, scientific detail was either translated or omitted if it was not vital to understanding the concept at hand.
} 
Table 1. Common Misconceptions and Their Underlying Assumptions

\begin{tabular}{|c|c|c|c|c|}
\hline Question & Correct response & Respondent answer & $\begin{array}{l}\text { Number of } \\
\text { times mentioned }\end{array}$ & Broad underlying assumption \\
\hline $\begin{array}{l}\text { What do wild salmon } \\
\text { eat? }\end{array}$ & Salmon are carnivores & $\begin{array}{l}\text { Aquatic vegetation } \\
\text { Other fish } \\
\text { Micro organisms in the water }\end{array}$ & $\begin{array}{l}9 \\
8 \\
2\end{array}$ & $\begin{array}{l}\text { Many respondents believe that } \\
\text { salmon are omnivores or herbivores. }\end{array}$ \\
\hline What is canola? & $\begin{array}{l}\text { An oilseed crop grown } \\
\text { in the prairie provinces } \\
\text { of Canada (Manitoba, } \\
\text { Alberta and } \\
\text { Saskatchewan) }\end{array}$ & $\begin{array}{l}\text { Some kind of grain } \\
\text { Wheat } \\
\text { Corn } \\
\text { Oilseed, derived from rapeseed, } \\
\text { mustard family } \\
\text { No idea }\end{array}$ & $\begin{array}{l}6 \\
5 \\
2 \\
2 \\
2\end{array}$ & $\begin{array}{l}\text { Most respondents did not } \\
\text { differentiate between oilseeds and } \\
\text { other grains and were unaware of } \\
\text { any issues specific to canola. }\end{array}$ \\
\hline $\begin{array}{l}\text { Where do the ingredients } \\
\text { in farmed salmon feed } \\
\text { come from? }\end{array}$ & $\begin{array}{l}\text { South America (protein } \\
\text { component) and North } \\
\text { America for the rest }\end{array}$ & $\begin{array}{l}\text { Canada } \\
\text { USA } \\
\text { Asia }\end{array}$ & $\begin{array}{l}15 \\
3 \\
2\end{array}$ & $\begin{array}{l}\text { Most respondents were unaware that } \\
\text { any of the ingredients in farmed } \\
\text { salmon feed came from South } \\
\text { America. }\end{array}$ \\
\hline
\end{tabular}

Note: totals may not sum to $100 \%$ as individuals could offer multiple responses

tions would hinder the comprehension of new information and were addressed in the risk communication experiment (see Table 1).

The experiment itself was an in person survey in three sections. In the first section, the respondent was asked a series of multiple choice type questions concerning GE technologies and salmon aquaculture. These questions were intended to test the prevalence of the common misconceptions discovered during the mental model interviews. In part two, the respondent was given three different methods of communicating the risks and benefits of using GE salmon feeds: a flowchart; a case study; and Frequently Asked Questions (FAQ). Each format was based on the expert model flowcharts. In the final section, the respondent was re-tested on the questions from section one and asked to rate the methods of communication in section two on several criteria. In total, forty-nine respondents participated in this portion of the experiment.

\section{Data and Results}

The following section will present an overview of survey results and their relation to each of our research questions.

\subsection{Influence on respondents' understanding of factual information}

As mentioned previously, individuals who participated in the mental model interview component of this paper held a number of common misconceptions about the salmon aquaculture industry and GE technologies. In the last portion of this study, (the in person survey), we asked respondents a number of questions designed to test the prevalence of these common misconceptions in a larger sample of people. Each of the questions was posed in a multiple-choice type format, and each potential choice was an actual answer given by a mental model interview respondent. Figure 2 hows three of the multiple choice type questions included in the survey.
The individuals that we recruited for this survey experiment represented many diverse cultures, age categories, and occupations, but none were experts in any subjects relevant to this experiment. The only filter for participation was that the individual had to be involved in their household's purchasing decisions. Individuals were recruited at a downtown Vancouver office building, an aquatic center, The University of British Columbia, and a church. The main goal of the recruitment process was to create a sample that had a fairly even gender split and did not overly represent any particular section of the larger population of Vancouver, BC. It is important to note that although many of the findings presented in this paper are statistically significant, they cannot be used to represent the views of the general population in Vancouver. This research should instead be viewed as a pilot study that experimented with new ways of communicating complex scientific information. Studies with larger samples of individuals will occur in the future and will be based on the findings presented here.

The survey results confirmed the presence of common misconceptions in the larger sample of respondents. According to the McNemar test for statistical significance, each of the results shown in Figure 3 is statistically significant (Daniel, 1990). ${ }^{*}$ Less than half $(n=22)$ could correctly answer question regarding what wild salmon ate in nature, and only a mere eight could accurately tell us where the protein component for farmed salmon feed comes from. However, our results also indicate that an individual's misconceptions can change when that person is offered accurate information that

\footnotetext{
* The McNemar Test measures the significance of the difference between responses before and after expert information is disseminated. It is often referred to as "the McNemar test for the significance of changes", as it measures the number of individuals who respond differently after being exposed to new information or a new condition. Hence, it is a test of the effectiveness of this risk communication effort.
} 
1. What do wild salmon eat in nature? (please check off all that apply)

$\square$ Aquatic plants

$\square \quad$ Fish that share their aquatic environment

$\square \quad$ Tiny nutrients found in ocean water

2. What is canola? (please check off all that apply)
$\square$ An oilseed plant
$\square \quad$ A kind of wheat
$\square \quad$ A kind of sunflower
$\square \quad$ A kind of corn
$\square \quad$ A synthetic (man made) oil

3. Where does the protein component of farmed salmon feed currently come from? (please check off all that apply)
$\square$ Canada
$\square \quad$ South America
$\square \quad$ United States
$\square \quad$ Japan
$\square$ Europe

Figure 2. Survey questions representing commonly held misconceptions discovered during the mental models interviewing process.

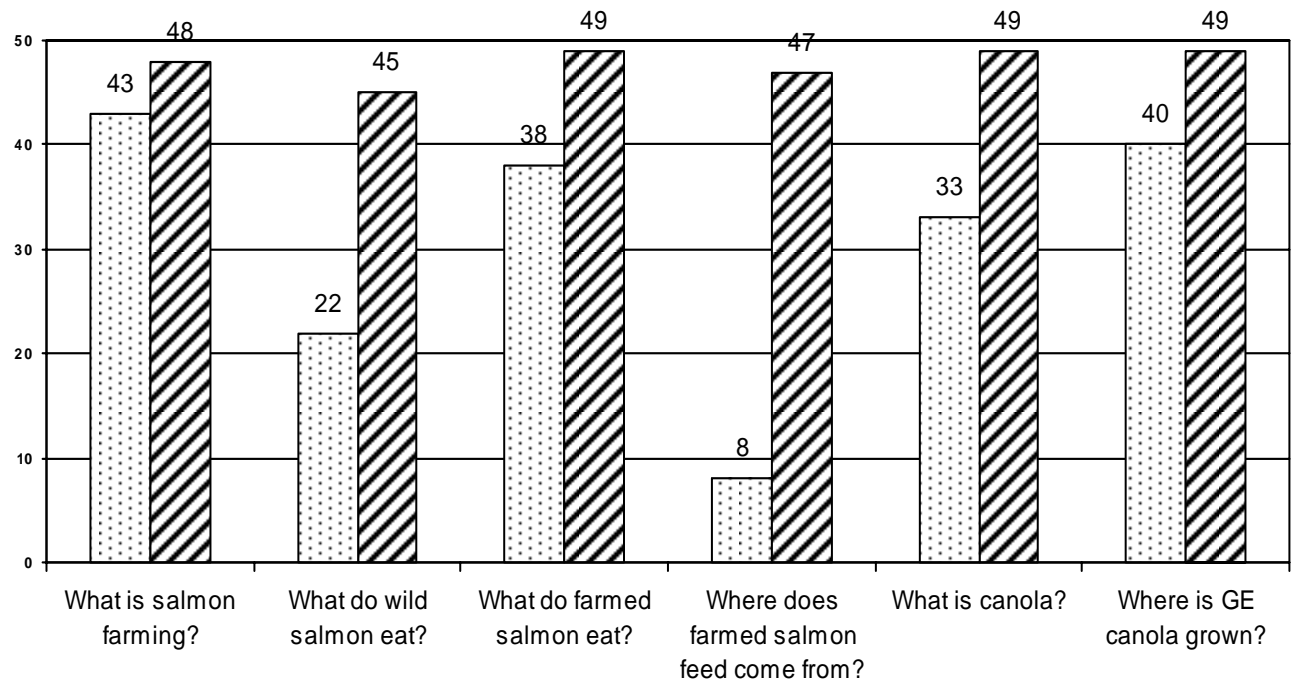

$\square$ Before reading expert information $\square$ After reading expert information

Figure 3. Number of correct responses given before and after reading expert information $(\mathrm{n}=49)$. 
Table 2. Rating the Methods of Communication Against Various Criteria

\begin{tabular}{llll}
\hline How do you rate each method of communication in terms of...? $(\mathrm{n}=49)$ & Overall favorite & Second favorite & Worst overall \\
\hline Trustworthiness & FAQ & Case study & Flowchart \\
Easiest to understand & FAQ & Case study & Flowchart \\
Enjoyable to read & Case study & FAQ & Flowchart \\
Contained the most useful information & FAQ & Case study & Flowchart \\
Liked the best overall & FAQ & Case study & Flowchart \\
\hline
\end{tabular}

contradicts their mistaken beliefs. Figure 3 shows the number of respondents who gave correct answers to our multiple choice questions both before and after they had received accurate information in section two of the survey.

It is interesting to note that although most people from the mental model interviews did not know what salmon aquaculture was, what farmed salmon ate, what canola was, or where it came from, many of the respondents who answered the survey did. This could indicate that many individuals within the larger population do not hold misconceptions about the canola plant and other issues. However, it may demonstrate that it is simply easier for people to correctly answer these sorts of questions when aided through a multiple choice type question format. In the mental model interviews, the respondents were asked open ended questions and given no 'hints'. In the survey, the correct answer is always offered to the respondent as one of the potential choices.

A surprising trend seems to be emerging between how respondents rated the methods of communication from section two of the survey, and how effective each one was in correctly conveying expert information. There seems to be no correlation between the effectiveness of each method of communication and its popularity. We had assumed that our respondents would like the communication methods that allowed them to answer the most correct answers in section three of the survey. However, the popularity of each communication method may not predict how effective that method was. Table 2 shows how all forty-nine respondents rated the methods of communication according to a pre-determined set of criteria.

Overall, the most trustworthy method of communication was the FAQ format. Respondents also rated the FAQ format as the easiest to understand, the one that contained the most useful information, and the one they liked best overall. The case study was rated as the most enjoyable to read. The flowchart did not lead in any of our categories; in fact, it was rated the worst overall in each category by the majority of respondents.

Section three of the survey also employed empirical testing methods to capture the effectiveness of each method of communication from section two. In order to ensure the

\footnotetext{
*Please note that the charts in this report give only the number of respondents and not percentages. Due to the small sample size, percentages would be misleading. As well, individuals could offer multiple responses to each question. Therefore, the answers are mutually exclusive.
}

reliability of the results, the answers to each set of questions could only be found in the method of communication being examined. For example, the answers to the flowchart questions could only be found in the flowchart, the case study questions could only be found in the case study, etc (see Table 3).

Although the majority of respondents reported liking the FAQ method of communication the best on almost every criterion, this method was not the most effective in conveying information overall. On average, it produced correct responses for thirty-nine people. The case study also elicited correct responses for an average of thirty-nine people. The flowchart, rated the worst overall on every single criterion, averaged the most correct responses for forty-one people.

The differences between these averages are not statistically significant, but they may indicate the beginning of a trend. Given how each method was rated by respondents, and their personal comments and complaints regarding the flowcharts, we expected it to produce significantly fewer correct answers. This was not the case. Although no conclusions can be reached at this time due to the slight variation between the results, it will be interesting to test this correlation between popularity and effectiveness in future research studies with larger samples of people.

\subsection{Influence of consumer confidence levels}

Overall, confidence levels were improved for most participants. Figure 4 shows the number of respondents who said they were 'not at all confident' in their purchasing decisions regarding salmon aquaculture and GE food products both before and after they had reviewed expert information. Overall, fewer individuals said they were 'not at all confident' by the end of the survey. While twenty-four people said they were 'not at all confident' in their salmon aquaculture food product purchasing decisions at the beginning of the experiment, only nine said they were still not confident by the end. Twenty-three people said they were 'not at all confident' in their purchasing decisions regarding GE food products at the beginning of the survey. Although this number decreased by the end of the survey, fourteen respondents remained 'not at all confident' (see Figure 4).

Figure 5 shows the amount of people who said they were quite, very, or extremely confident in their salmon aquaculture and GE food purchasing decisions at the beginning of the survey and at the end. It seems that our expert information 
Table 3. Overall Effectiveness of Communication Methods

\begin{tabular}{|c|c|}
\hline Question & $\begin{array}{l}\text { Correct response } \\
(\mathrm{n}=49)\end{array}$ \\
\hline \multicolumn{2}{|l|}{ Question concerning environmental risks and benefits (FAQ format) } \\
\hline 1) Farmed salmon would probably have an easier time digesting GE canola feed & 28 \\
\hline 2) GE canola could lead to a loss of genetic diversity and biodiversity & 39 \\
\hline 3) If a animal eats GE feed, it then becomes GE & 41 \\
\hline 4) It is possible for different GE canola plants to become super weeds & 46 \\
\hline 5) Farmers use les herbicide with GE canola crops & 43 \\
\hline 6) GE feed leads to a cleaner aquatic environment & 37 \\
\hline Average & 39 \\
\hline \multicolumn{2}{|l|}{ Questions concerning economic risks and benefits (flowchart) } \\
\hline 1) GE low phytase feed could be beneficial to poultry and pig farmers & 48 \\
\hline 2) If Canada stopped importing traditional feed it would devastate the South American economy & 46 \\
\hline 3) GE feed would increase overall production costs of salmon farming & 39 \\
\hline 4) GE canola could cause organic farming operations & 34 \\
\hline 5) GE canola is grown mostly in Ontario & 46 \\
\hline 6) GE canola could reduce amounts of fossil fuels currently used in salmon aquaculture industry & 34 \\
\hline Average & 41 \\
\hline \multicolumn{2}{|l|}{ Questions concerning social risks and benefits (case study) } \\
\hline 1) What term is used to imply GE plant is very similar/as safe as to its non-GE counterpart & 34 \\
\hline 2) Human health risks of GE canola are very well understood in Canada & 26 \\
\hline 3) GE canola could lead to loss of independence for traditional farmers & 43 \\
\hline 4) Many animal health problems are linked to GE feeds & 43 \\
\hline 5) Feed costs are a small proportion of total salmon farming production costs & 41 \\
\hline 6) Wild salmon in stores is always fresher than farmed salmon & 48 \\
\hline Average & 39 \\
\hline
\end{tabular}

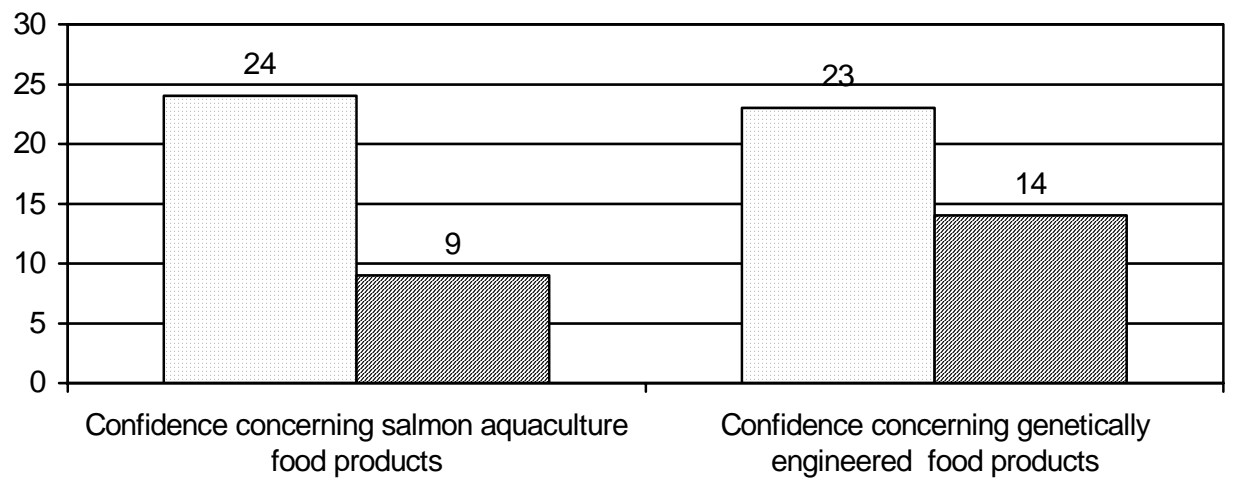

$\square$ Respondents who were "Not at all confident" before reading expert information Respondents who were "Not at all confident" after reading expert information

Figure 4. Respondents' reported confidence levels before and after reading expert information (A) $(n=49)$. 


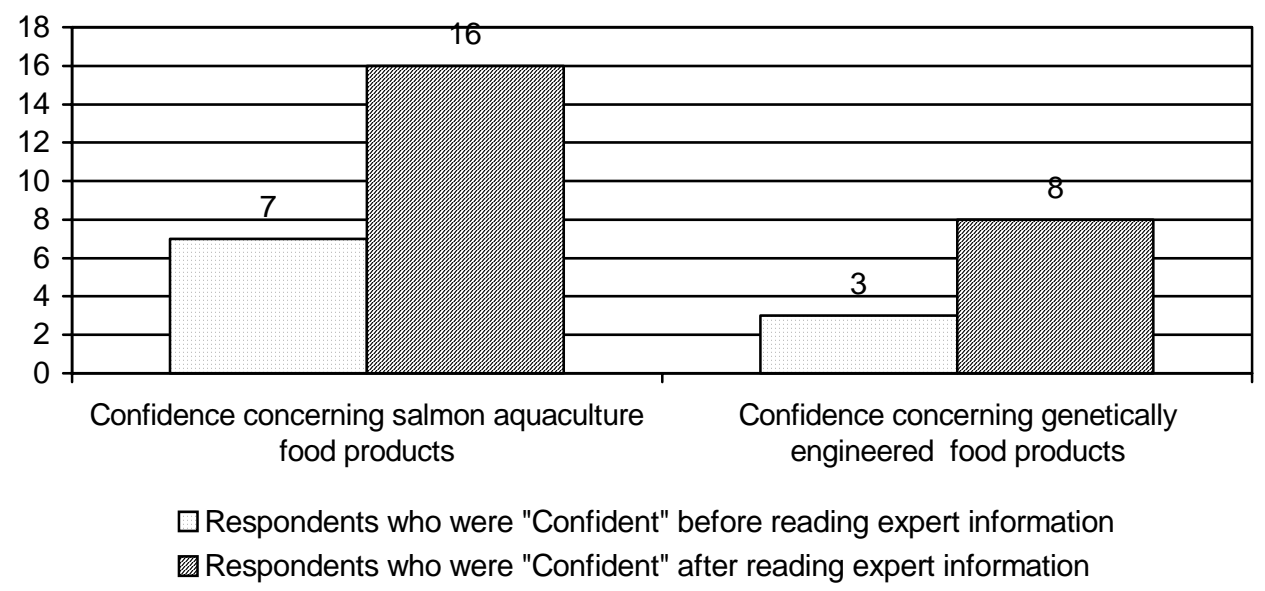

Figure 5. Respondents' reported confidence levels before and after reading expert information $(B)(n=49)$.

was more successful in raising consumer confidence levels regarding salmon aquaculture food purchasing decisions than GE food purchasing decisions. T-tests show that a statistically significant number of people had become more confident in their salmon aquaculture purchasing decisions. The same cannot be said of confidence levels concerning GE food purchasing decisions. By the end of the survey, nine more people said they were confident in their salmon aquaculture foods purchasing decisions, while only five more were confident in their GE food purchasing decisions. Although confidence levels were raised overall, many people apparently need even more information or assurance before they can be completely confident in these types of purchasing decisions.

\subsection{Acceptance of an issue}

In sections one and three of the survey we asked respondents how important certain factors were in their decisions to purchase food products. Among some of the factors were: the human health impacts of consuming that food; taste; traceability; convenience; and knowing that the food had not been genetically engineered or had consumed feeds that had been genetically engineered.

Twenty-two respondents said that knowing their food had not been genetically engineered or had eaten GE feeds was very or extremely important to them in section one of the survey, but only fifteen chose this response in the re-test. By the end of the experiment, seven respondents had decided that knowledge concerning the genetic modification of their food was less important to them after examining expert information on the subject. Yet their concerns in other areas relating to the foods they consumed remained about the same. As we learned through responses not reported on in this paper, our respondents were more inclined to believe that GE technologies that positively impacted industry or human health were acceptable and those that improved appearance or introduced genes from animals or bacteria were not. Perhaps we can infer that our respondents view GE technologies described in this experiment as useful to the salmon aquaculture industry without being unnecessarily harmful to human health, and therefore acceptable (see Figure 6).

We asked respondents to identify concerns that they had about purchasing farmed salmon fed with GE canola. Before reading expert information, the most commonly mentioned fears were that fish fed on transgenic feed amplified or compounded pre-existing concerns held by respondents $(n=22)$. Many also believed that feeding fish GE canola feed was "unnatural" $(n=26)$. After reading expert information on the subject, concerns in most areas decreased. The exception was fears regarding how these fish may impact the environment. In the re-test, nine more people expressed their concerns in this area.

The expert information had no impact on respondents who worried that GE canola fed fish might be bad for their health. Fourteen people stated this as a concern before they read the expert information and fourteen people stated it during the re-test. Although twelve people thought farmed salmon might become genetically engineered after consuming a GE feed, only five still believed this after reading section two (See Figure 7).

People who reported having no concerns about farmed salmon fed with South American fish increased from four to ten after reading our expert information. The expert information also influenced people's concerns regarding South American health and environmental standards (-7), and fair trade between Canada and South American fishermen (-11). Fewer respondents maintained their concerns in these areas after reading section two of the survey. However, the expert information increased the fears of respondents in two areas including how this practice might impact the South American environment (+6), and the Canadian aquaculture industry (+5) (See Figure 8). 


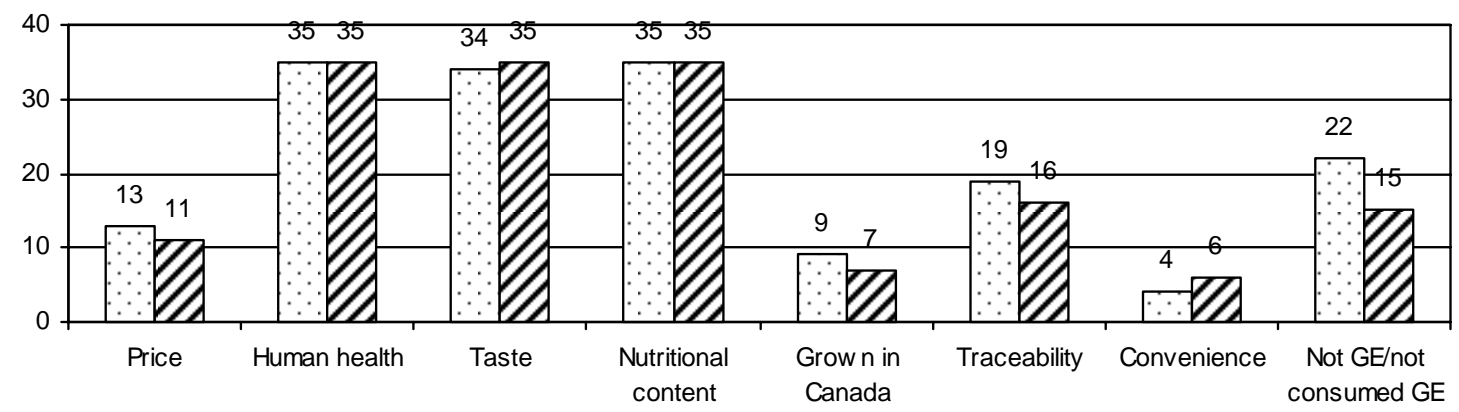

$\square$ Before reading expert information-Very/extremely important $\square$ After reading expert information-Very/extremely important

Figure 6. Importance of various factors in respondents' food purchasing decisions $(n=49)$.

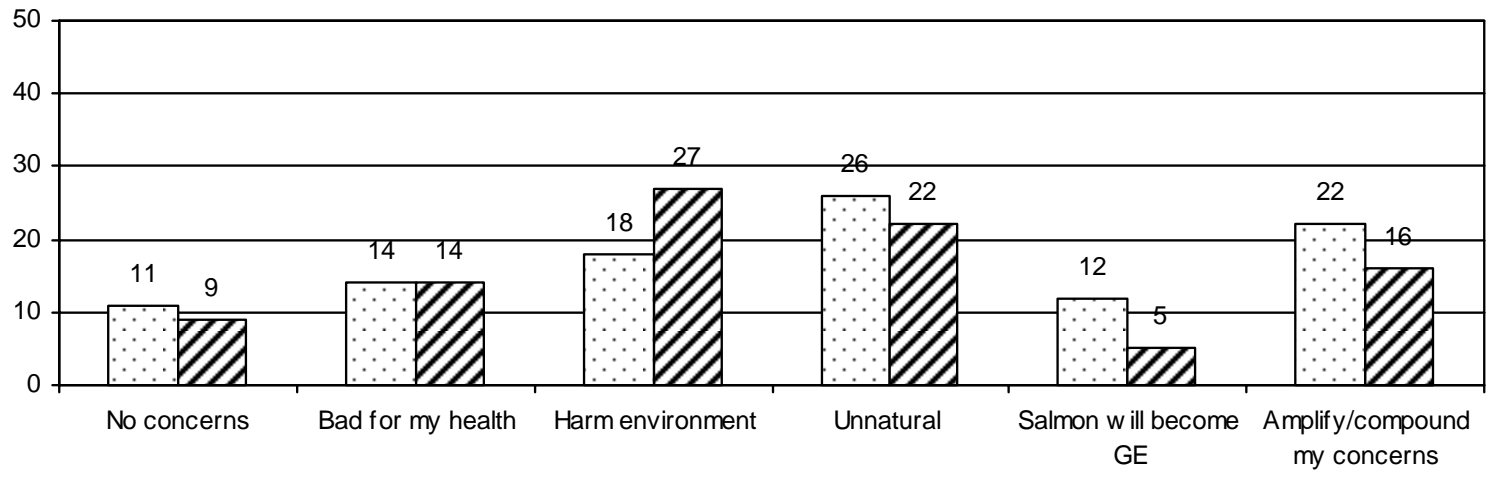

$\square$ Before reading expert information

D After reading expert information

Figure 7. Respondents' concerns regarding farmed salmon fed with GE canola $(n=49)$.

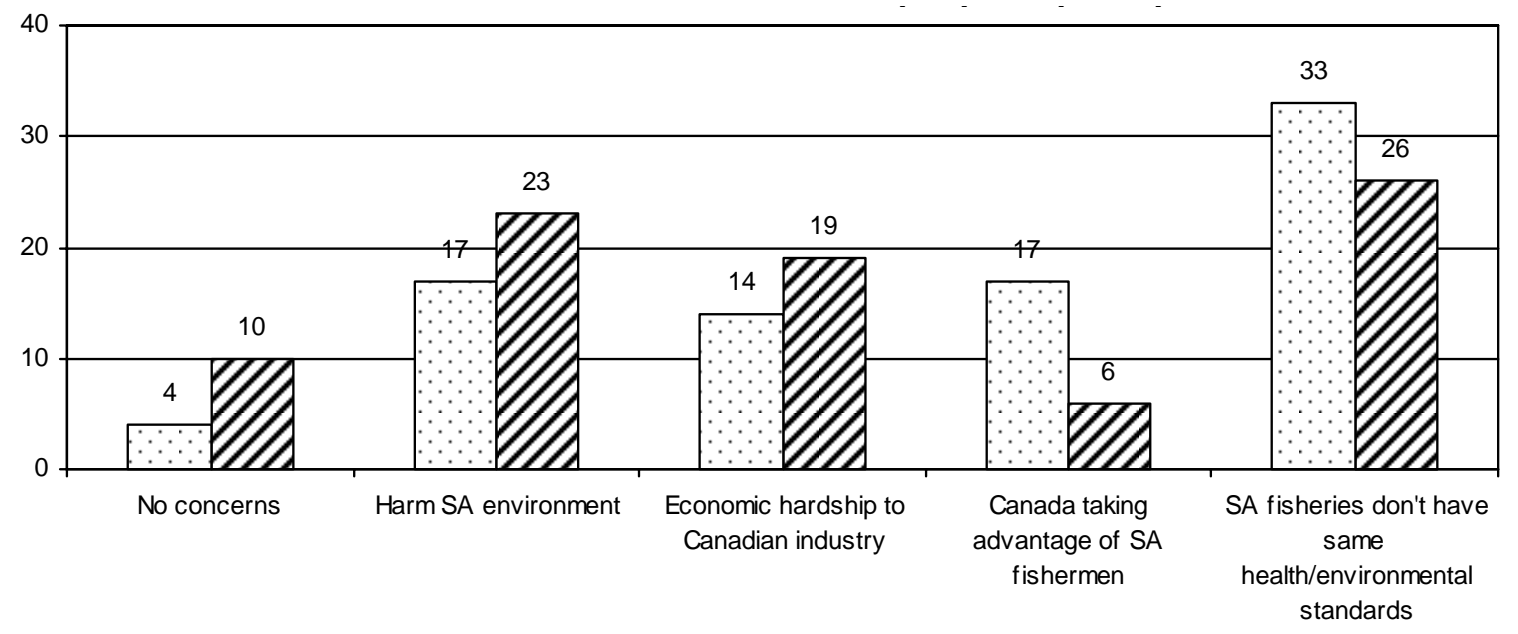

$\square$ Before reading expert information $\square$ After reading expert information

Figure 8. Respondents' concerns regarding farmed salmon fed with South American (SA) fish (n = 49). 


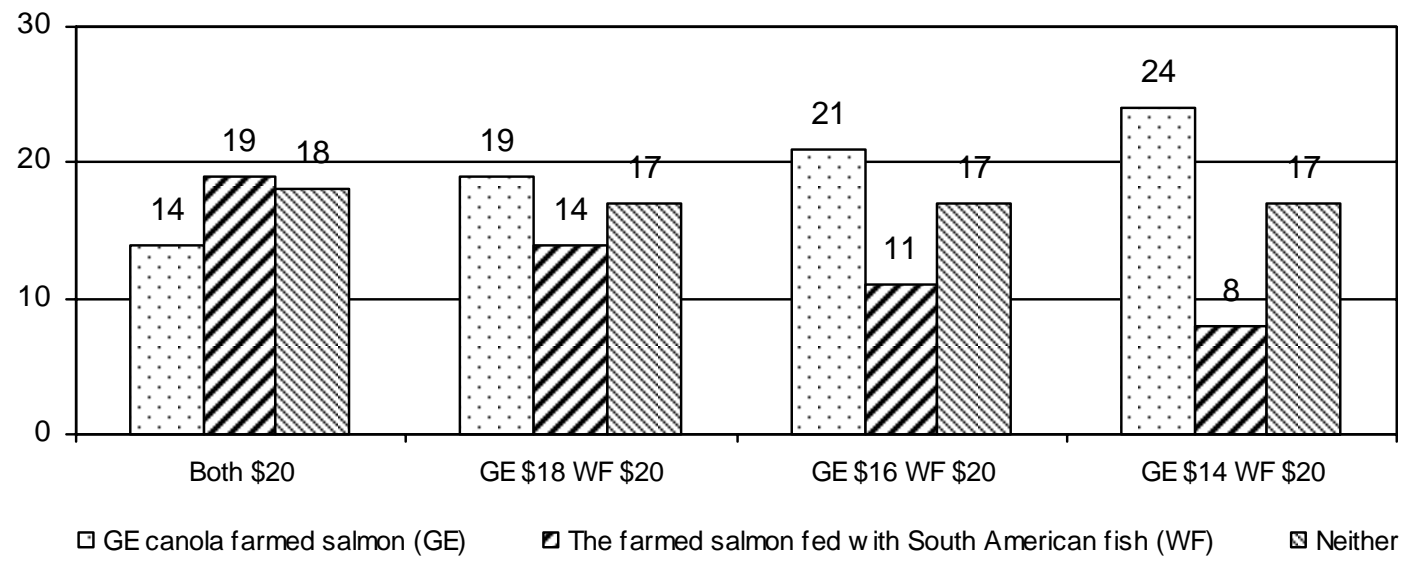

Figure 9. Popularity of fish at different price comparisons $(n=49)$.

\subsection{Impact of expert information on purchasing decisions}

We were interested in how price would influence a respondent's decision to purchase salmon food products after they had examined our expert information. We gave individuals the choice between purchasing a farmed salmon fed with wild fish meal from South America and farmed salmon fed with GE canola. We started by making both farmed salmon worth twenty dollars. We then kept the price of the fish fed with wild fish from South America constant at twenty dollars, and decreased the price of the GE canola fed salmon by two dollar intervals (see Figure 9).

We found that price did have an influence on purchasing decisions. When both fish were twenty dollars, five more respondents chose to purchase the farmed salmon fed with wild fish meal, rather than the GE canola fed farmed salmon. If the GE canola fed salmon was at least two dollars cheaper than the other fish, most people said they would be more likely to purchase it. When the GE canola fed farmed salmon was eighteen dollars, five more respondents chose this farmed salmon rather than the one fed with wild fish meal. When the price of the GE canola fed farmed salmon was another two dollars cheaper, ten more people chose to purchase it instead of the other fish. When the price dropped another two dollars, making the GE canola fed farmed salmon fourteen dollars, twenty-four chose to purchase it and only eight still wanted to purchase the farmed salmon fed with wild fish meal. It should also be noted that the number of people who said they would purchase neither fish did not change as the price of the fish was altered. This led us to believe that those who do not purchase farmed salmon, for whatever reason, are less likely to be influenced by the price of the fish.

The last question in the survey asked respondents to rate how the experiment had impacted their purchasing decisions regarding salmon aquaculture food products. We asked them to choose between three statements (see Figure 10).

Of the 49 respondents who answered this question, eighteen said the information provided to them would not impact their decision ( 37\%). A similar amount said it would impact their decision; it would make them less likely to purchase this fish $(\mathrm{n}=19,39 \%)$. The remaining thirteen said the informa-

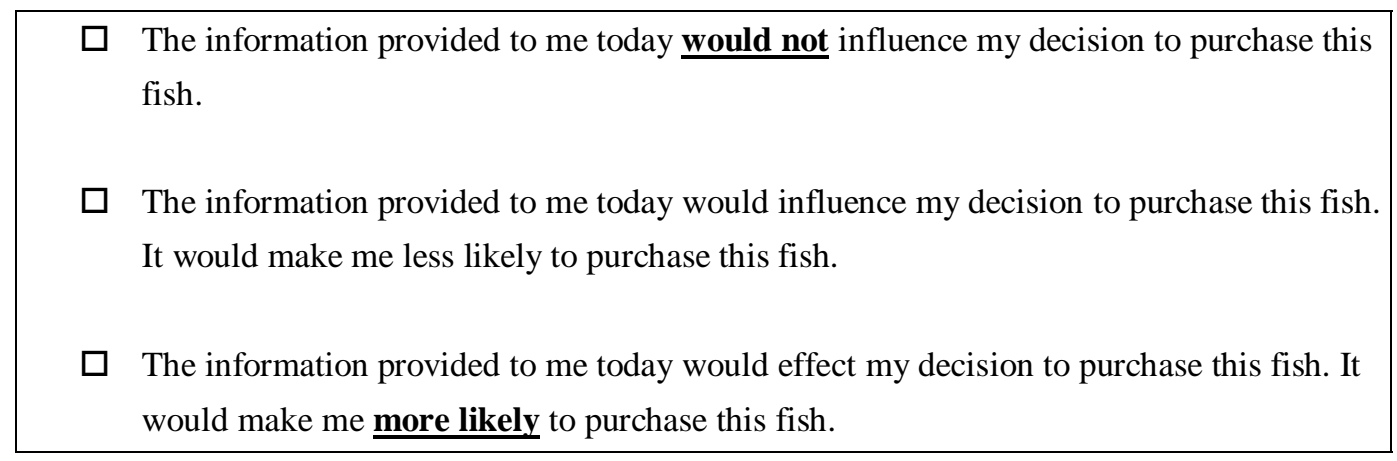

Figure 10. Impact of expert information on purchasing decisions. 
tion would make them more likely to purchase GE canola fed farmed salmon $(\sim 27 \%){ }^{*}$ In other words, our experiment appeared to successfully impact (either positively or negatively) the purchasing decisions of thirty-two survey respondents or almost two thirds of our sample (See Figure 11).

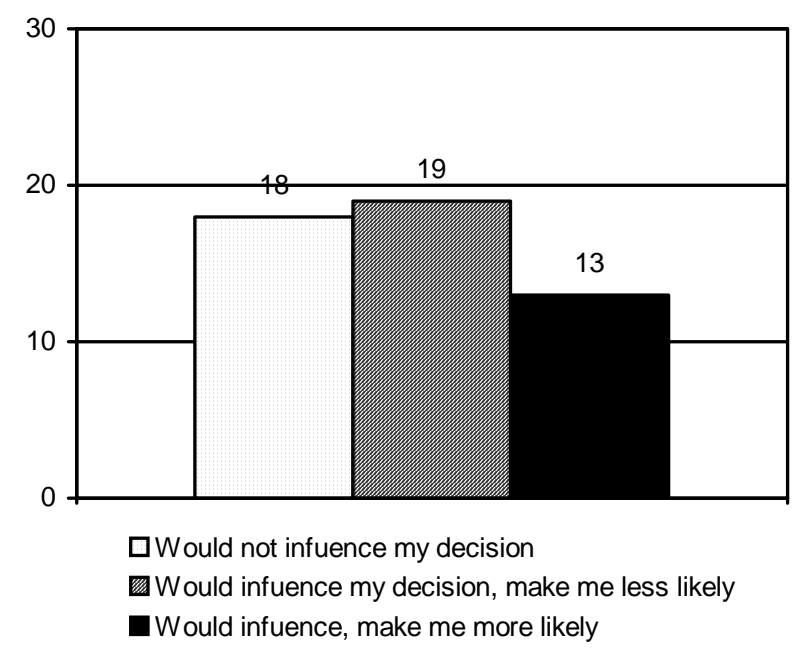

Figure 11. Impact of expert information on decision to purchase GE canola fed farmed salmon $(n=49)$.

\section{Discussion}

Canadian consumers have a right to make informed decisions regarding their food purchases. To make an informed decision, the public must have access to unbiased information concerning the known environmental, economic, and social risks and benefits of their choices. Communication between experts and the general public is therefore essential. However, this process often requires more effort than simply providing the public with scientifically accurate information. The mind of a consumer is not a tabula rasa. Each individual will have a mental model of how their highly complex world operates. These mental models are used to explain and predict the world around them and are informed by their life experiences and worldviews (Morgan et al., 2002). As demonstrated in this research paper, these mental models may also contain mistaken beliefs that can hinder the comprehension of new information.

Given the influence of mental models, the media, and other factors, effective communication regarding the risks and benefits of new technologies used in food production requires a cooperative effort between Canadian consumers, risk communicators, and experts. Although experts can tell us what the actual risks and benefits of new technologies are,

\footnotetext{
*Although our $\mathrm{n}$ size for this question is forty nine, our results show that 50 people answered this question. One person gave two responses despite the fact they were asked to choose only one. For this reason, the percentages given in the section do not sum to $100 \%$, and are not completely accurate.
}

they often perceive and rate risk differently than laypeople. As a result, their recommendations do not always reflect the values of Canadian consumers. Risk communicators are needed to bridge the gap that occurs between the expert's and layperson's perceptions of risk. The layperson's mental models of the technology are captured by the risk communicator who then challenges commonly held misconceptions while offering the layperson scientifically accurate and diverse information in a context that is meaningful to them. We found that flowcharts are an effective way to capture the expert view. The next step is to determine which method of communication most effectively communicates expert information to laypeople.

\section{Conclusions}

It seems clear that effective risk communication is possible even with controversial topics. That said, more research is required to determine why certain methods of communication work better than others with some respondents. In this experiment, we found that the popularity of a communication method did not seem to predict how effective that method would be in producing correct responses. Overall, the most trustworthy method of communication was the FAQ format. Respondents also rated the FAQ format as the easiest to understand, the one that contained the most useful information, and the one they liked best overall. The case study was rated as the most enjoyable to read. The flowchart did not lead in any of our categories; in fact, it was rated the worst overall in each category by the majority of survey respondents. Yet although most individuals reported liking the FAQ method of communication the best on almost every criterion, this method was not the most effective in conveying information overall. The flowchart, rated the worst overall on every single criterion, averaged the most correct responses for forty-one people.

Of course these results are very close, but they may indicate a trend. Given how each method was rated by respondents, and our respondents' comments and complaints regarding the flowchart methodology, we expected it to produce significantly fewer correct answers. This was not the case. Although no conclusions can be reached at this time due to the insignificant variation between the results, it would be interesting to test this correlation between popularity and effectiveness in future research studies with larger samples of people.

It is important to remember that we are not acting as advocates of the salmon aquaculture industry or GE technologies. Our intention is simply to experiment with different methods of communicating complex scientific information to Canadian consumers. Spending a substantial amount of time with each mental model interviewee and survey respondent gave us the opportunity to gain a greater understanding of our respondents' perceptions of these issues. Most enjoyed participating in this risk communication experiment and were eager to learn about controversial technologies. Almost one quarter wrote brief notes in the margins of their surveys 
thanking us for the opportunity to participate in an "educational" experiment.

This study was successful in many respects. The materials in the experiment impacted most individuals purchasing decisions. The process increased our respondents overall acceptance of certain food products, and perhaps more importantly, their confidence levels regarding their salmon aquaculture and GE food purchasing decisions. Results also demonstrated that the risk communication methods included in the in person survey could successfully correct many commonly held misconceptions. That said, one quarter of survey respondents told us through hand written notes that they were still concerned about the amount of uncertainty surrounding these issues. They were also worried about the unknown long-term impacts of salmon aquaculture and GE foods, and felt they needed even more information to make competent food purchasing decisions.

Of the forty-nine people we spoke with, all were willing to consider new information about GE technologies and the salmon aquaculture industry. As mentioned earlier in this paper, a number of ENGO's have actively engaged in anti-farmed salmon campaigns in BC. In the past, the salmon aquaculture industry has not made a significant effort to defend their industry. This stance is unfortunate given that the results of our research seems to show that many people hold misconceptions about this industry and are eager to learn more about salmon aquaculture. It is our hope that the results presented here will encourage others to implement similar studies in the future in order to foster an understanding of novel technologies and misunderstood industries.

Acknowledgments. Financial support from AquaNet, the Center for the Integrated Study of Human Dimensions of Global Change at Carnegie Mellon University, and the University of British Columbia are highly appreciated. Special thanks also to my MA advisor Dr. Tim McDaniels, my MA committee members Dr. Les Lavkulich and Dr. Terre Satterfield, the Individual Interdisciplinary Studies Graduate Program, Michael McDonald and the Health Research and Policy Training program through the W. Maurice Young Centre for Applied Ethics at the University of British Columbia. Lastly, I would like to acknowledge assistance from Joey Mikawoz, all of the experts who were consulted during this study, and the individuals who participated in our interviews and surveys.

\section{References}

Agnew, J. (1993). Representing space-space, scale and culture in social science, Place, Culture and Representation, Routledge.

Basseau, K. (1993). Place, Culture and Representation, Routledge.

Bazerman, M. (1994). Biases emanating from anchoring and adjustment, Behavioral and Managerial Decision Making $4^{\text {th }}$ Edition, John Wiley \& Sons Inc.

Branswell, H. (2004). Health Canada Wants a Grade on SARS Risk Communications: Expert Gives an F. http://mediresource.sympa tico.ca/channel_health_news_detail.asp?channel_id=60\&menu_ item_id=4\&news_id=3028 (accessed April 25, 2004).

Betts, K.S. (2004). Improving Fish Food, Technology News. http:// pubs.acs.org/subscribe/journals/esthag-w/2004/feb/tech/kb_fishf ood.html (accessed February 20, 2004).

British Columbia Environmental Assessment Office (1997). Salmon
Aquaculture Review-Consolidated List of Recommendations. http:// www.intrafish.com/laws-and-regulations/report_bc/v1recs.htm (accessed April, 2004).

Canada Customs and Revenue Agency (Canada). http://www.ccra-ad rc.gc.ca/ (accessed April, 2003).

Canadian Aquaculture Industry Alliance, Media Corner. CAIA Director Speaks Out On 'Farmed \& Dangerous' Campaign. http://ww w.aquaculture.ca/English/PressReleases/CAIA_PressR eleases37.html (accessed March, 2004).

Canadian Center for Policy Alternatives and Shy. The Fight for the Family Farm, Quarterly Review: Economic and Social Trends in Manitoba, Winnipeg Manitoba Winter (Canada). www.policyal ternatives.ca/mb (accessed April 1, 2003).

Canola Council of Canada. Truths and Myths about Canola (Canada). www.scdc.sk.ca/html/educ.html (accessed April 1, 2003).

Daniel, W.W. (1990). Applied Nonparametric Statistics, $2^{\text {nd }}$ Edition, PWS-Kent Publishing Company, Boston, Massachusetts.

David Suzuki Foundation. Why you shouldn't eat Framed Salmon. http://www.davidsuzuki.org/files/PSF_Salmon_Brochure.pd (accessed February 20, 2004).

Dosanjh, B.S., Higgs,D.A., McKenzie, D.J., Randall, D.J., Eales, J.G., Rowshandeli, N., Rowshandeli, M. and Deacon, G. (1998). Influence of dietary blends of menhaden oil and canola oil on growth, muscle lipid composition and thyroidal status of Atlantic salmon (Salmo salar) in sea water. Biochem., 19, 123-134.

Engineering and Public Policy Carnegie Mellon University (2002). Risk Analysis and Risk Communication. http://www.epp.cmu. edu/research/risk.html (accessed April 25, 2004).

Fisheries and Oceans Canada (DFO). Aquaculture Biotechnology Topics: Biotechnology to Help Develop Better Salmon Feeds (Canada). http://www.pac.dfo-mpo.gc.ca/aquaculture/topics/sal monfeed_e.htm (accessed February, 2004).

Goldman, F. (2000). Make way for Frankenfish! Time, 155(9), 62-63.

Government of Manitoba, Agriculture and Food Agriculture Statistics (Canada). http://www.gov.mb.ca/agriculture/statistics/ (accessed April 1, 2003).

Gregory, R., Flynn, J. and Slovic, P. (1995). Technological Stigma. Am. Sci., 83(3), 220-223.

Health Canada Online (2004). Food safety and PCBs found in fish. www.hc-sc.gc.ca/english/media/releases/2004/factsheet_food.ht $\mathrm{m}+$ health+canada+farmed+salmon\&hl=en\&start $=1$ (accessed April 25, 2004).

Hoffman, S.M. and Oliver-Smith, A. (1999). The Angry Earth: Disasters in Anthropological Perspective, Routledge.

Holman, J.P. (2001). Experimental Methods for Engineers, $7^{\text {th }}$ Edition, McGraw Hill.

Hopki, M. (2003). Farmed Salmon Harbour Pollutants, Nature News Service. http://www.nature.com/nsu/040105/040105-10.html (accessed February 20, 2004).

Indian and Northern Affairs Canada, Kitasoo Aquafarms Ltd.-Salmon Farm Now in the Pink (2002). http://www.ainc-inac.gc.ca/nr/ecd /ssd/ma06_e.html (accessed March 25, 2002).

Kai, E. (1994). A New Species of Trouble: Explanations in Disaster Trauma and Community $1^{\text {st }}$ Edition, W.W. Norton \& Company.

Kasperson, R.E., Renn, O., Slovic, P., Brown, H.S., Emel, J., Gobel, R., Kasperson, J.X. and Ratick, S. (1988). The social amplification of risk: A conceptual framework. Risk Anal., 8(2), 177-187.

Kissil, W.G., Lupatsch, I., Higgs, D.A. and Hardy, R.W. (2000). Dietary Substition of Soy and Rapeseed Protein Concentrates for Fish Meal, and their Effects on Growth and Nutrient Utilization in Gilthead Seabream Sparus Aurata L. Aquat. Res., 31, 595601.

Kneen, B. (1999). Farmageddon: Food and the Culture of Biotechnology, New Society Publishers.

Krimsky, S. and Golding, D. (1992). Social Theories of Risk, Praeger. Leggatt, S.M. (2002). Clear Choices, Clean Waters, the Leggatt In- 
quiry into Salmon Farming in British Columbia, Report and Recommendations.

Leiss, W. (2001). In the Chamber of Risks: Understanding Risk Controversies, McGill-Queen University Press.

Lowenstein, G.F., Weber, E.U., Hsee, C. and Welch, N. (2001). Risk as feelings. Psychol. Bull., 127(2), 267-286.
McDaniels, T. and Longstaff, H. (2003). Structuring Hierarchies of Objectives as a Framework for Salmon Aquaculture Risk Management Decisions (unpublished).

Ministry of Agriculture Food and Fisheries (2003). Siting Fish Farms. http://www.agf.gov.bc.ca/fisheries/siting_reloc/siting.htm (accessed February 20, 2004). 